\title{
Coprecipitation Aided Synthesis of Bimetallic Silver Tungstate: A Response Surface Simulation of Sunlight-Driven Photocatalytic Removal of 2,4- dichlorophenol
}

\section{Rajashekara Rakshitha}

JSS Academy of Higher Education and Research

Bannimath Gurupadayya

JSS Academy of Higher Education and Research

Sake Haridass Kameshwari Devi

JSS Science and Technology University

Nagaraju Pallavi ( $\sim$ anupallavi@jssuni.edu.in )

JSS Academy of Higher Education and Research

\section{Research Article}

Keywords: Photodegradation, nanocomposite, phenolic pollutants, silver tungstate, 2,4-dichlorophenol, RSM

Posted Date: January 28th, 2022

DOI: https://doi.org/10.21203/rs.3.rs-1150607/v1

License: (c) (1) This work is licensed under a Creative Commons Attribution 4.0 International License. Read Full License

Version of Record: A version of this preprint was published at Environmental Science and Pollution Research on April 6th, 2022. See the published version at https://doi.org/10.1007/s11356-022-20062-y. 


\section{Abstract}

In the present study, the Response Surface Methodology (RSM) model was used to investigate the photocatalytic performance of silver tungstate $\left(\mathrm{Ag}_{2} \mathrm{WO}_{4}\right)$ in the removal of 2,4-dichlorophenol (2,4-DCP) under natural sunlight. The $\mathrm{Ag}_{2} \mathrm{WO}_{4}$ which has nanoflower-like structure was synthesized by a coprecipitation method. The synthesized photocatalyst was characterized for FESEM, TEM, EDX, XRD, FTIR, and UV-Vis spectroscopy. RSM was employed to scrutinize the suitable model to yield a profound pollutant removal rate. The four independent factors such as pollutant concentration, catalyst dosage, $\mathrm{pH}$, and contact time are simulated using RSM. $91 \%$ of 2,4-DCP degradation was achieved at a higher catalyst dosage and lower pollutant concentration with contact duration of $8 \mathrm{~h}$ in an alkaline $\mathrm{pH}$ condition. The coefficient of regression $\left(R^{2}\right)$ and probability value $(P)$ were 0.98 and 0.0472 , respectively, which confirmed the ideality of RSM modeling. The study discusses on the possible photocatalytic degradation mechanisms of 2, 4-DCP. The results showed a significant dependence of the photocatalytic removal of 2, 4-DCP on the functional parameters.

\section{Introduction}

Water is a life-giving element for all humans and is widely regarded as the most valuable resource for human civilization. (Zulfiqar et al. 2019). However, Due to the rapid industrialization, population increase, and unsustainable use of natural resources, providing clean and safe water has become a significant challenge in many developing countries, resulting in the release of a massive amount of hazardous organic pollutants into water bodies (Nagaraju et al. 2020). Among them, chlorophenols are primarily employed in manufacturing pesticides, herbicides, preservatives, dyestuffs, and petrochemicals (Yashas et al. 2019; Guerrero-Araque et al. 2020), which are hazardous and likely to pollute the natural water systems. Out of various chlorophenols contaminants reported, 2,4-dichlorophenol (2,4-DCP) is a very stable compound resistant to conventional degradation when exposed to direct natural sunlight (Humaira et al. 2020). This pollutant is highly toxic to humans and aquatic organisms because it can be absorbed through the skin pores and induce a variety of ailments related to skin, kidney functioning, and melanoma (Hu et al. 2018). Due to its high toxicity, it deserves special attention and immediate response. Thus, it is appropriate to effectively remediate 2,4-DCP to maintain the aquatic system for the human and animal health.

Over the last few decades, heterogeneous traditional water and wastewater treatment technologies have been replaced by photocatalytic degradation of organic contaminants, assuring high efficiency and no secondary pollutants (Rafiq and Majid 2020). Catalytic elimination of environmental pollutants driven by sunlight has gained considerable importance in the recent years (Singh and Soni 2021). The evolution of sunlight-driven remediation technology will highlight specific features such as high activity, good recyclability, high stability, and efficient recovery of a photocatalyst (Huang et al. 2017). The photocatalytic function of semiconducting materials is due to the light-induced generation of charge carriers, such as electrons and holes, which can travel to the surface of the material, exhibit distinctive redox characteristics, and drive chemical transformations. However, such materials are frequently 
affected by a harmful electron-hole recombination process, which reduces the lifetime of charge carriers and limits their availability for photocatalysis. Charge recombination would seem to have a direct impact on the photocatalytic performance of semiconducting materials. (Rafiq and Majid 2020). Hence, evaluation of different photocatalysts for pollutant degradation under sunlight is deemed essential to progress towards sustainability.

Further, nanoscale photocatalysts have revolutionized water/wastewater treatment (Adeleye et al. 2016). In the recent years of decomposition of organic pollutants using visible light illumination by silver-based photocatalysts such as $\mathrm{Ag}_{3} \mathrm{PO}_{4}, \mathrm{Ag}_{2} \mathrm{WO}_{4}, \mathrm{AgVO}_{3}, \mathrm{Ag}_{2} \mathrm{CO}_{3}, \mathrm{AgX}(\mathrm{X}=\mathrm{Cl}, \mathrm{Br}, \mathrm{I}), \mathrm{AgIO}_{3}, \mathrm{Ag}_{2} \mathrm{~S}$, and $\mathrm{Ag}_{2} \mathrm{MoO}_{4}$ have recently received considerable attention (Senthil et al. 2020), Due to its ease of reduction to metallic silver on its surface, silver tungstate (Ag2WO4) has received much interest, favoring the plasmon effect. (Andrade Neto et al. 2020). To date, different synthesis methods have been reported in the literature to obtain $\mathrm{Ag}_{2} \mathrm{WO}_{4}$ metastable phases. In particular, $\mathrm{Ag}_{2} \mathrm{WO}_{4}$ was successfully prepared by a precipitation method using a surfactant-assisted route in the presence of or polyvinylpyrrolidone (PVP) (Roca et al. 2017). Recently, Kokilavani and her team evaluated plasmonic $\mathrm{CoS} / \mathrm{Ag}_{2} \mathrm{WO}_{4}$ (cobalt-sulphide coupled with silver tungstate) for photocatalytic methylene blue removal and photocatalytic inactivation of $E$. coli and $B$. subtilis (Kokilavani et al. 2021). Similarly, Cen and coworkers fabricated $\mathrm{Ag}_{2} \mathrm{WO}_{4} / \mathrm{BiOCl}$ nanocomposite by coprecipitation for photocatalytic degradation of toxic dye, Rhodamine B dye (Cen et al. 2021).

To complement the photocatalytic degradation, the present study employed response surface methodology (RSM). RSM is a powerful design tool for developing new processes, modifying the design, and optimizing their performances (Nagaraju et al. 2017; Rafaely et al. 2021). By systematically adjusting all variables at the same time, it is the most reliable and empirical statistical technique for analyzing the influence of various process parameters on photocatalytic degradation. (Zulfiqar et al. 2019). For instance, Malika and Sonawane employed RSM to simulate the sono-photocatalytic removal of Rhodamine B using bismuth-doped titanium dioxide, supported montmorillonite nanofluid (Malika and Sonawane 2021). Likewise, recently, Ataei and their team studied the photodegradation of antibiotics, where the process's optimization and modeling were carried out using RSM (Ataei et al. 2021).

The present study focuses on the photodegradation of 2,4-DCP with $\mathrm{Ag}_{2} \mathrm{WO}_{4}$ prepared by soft-chemical technique and thoroughly characterized to uncover all the essential physico-chemical and photocatalytic properties. RSM was used for modeling and experimental validation for the removal of 2,4 DCP under natural sunlight with dependent parameters such as $\mathrm{pH}$, contact time, pollutant concentration, and catalyst dosage. The study proposes the degradation mechanism and anticipates the potential application of the system for water/wastewater treatment.

\section{Materials And Methods}

\section{Preparation of $\mathrm{Ag}_{2} \mathrm{WO}_{4}$}


Silver nitrate $\left(\mathrm{AgNO}_{3}\right)$, sodium tungstate $\left(\mathrm{Na}_{2} \mathrm{WO}_{4} \cdot 2 \mathrm{H}_{2} \mathrm{O}\right)$, polyvinylpyrrolidone (PVP - $\left(\mathrm{C}_{6} \mathrm{H}_{9} \mathrm{NO}\right)_{n} \mathrm{M} . \mathrm{W}$. 40.000), and ammonium hydroxide $\left(\mathrm{NH}_{4} \mathrm{OH}-30 \%\right)$ were obtained from Sigma-Aldrich, India, and were used without any modifications. The deionized water was used as a solvent throughout the study. The synthetic route was in accordance with the earlier report by Neto and the team with slight modification (Andrade Neto et al. 2020). $40 \mathrm{~mL}$ of $4 \mathrm{mM} \mathrm{AgNO3}$ was typically held under magnetic stirring until full solubilization was achieved.

The $\mathrm{pH}$ was then adjusted to 10.0 by adding ammonium hydroxide solution (I). Simultaneously, $40 \mathrm{~mL}$ of $2 \mathrm{mM} \mathrm{Na} 2 \mathrm{WO} 4.2 \mathrm{H} 2 \mathrm{O}$ was preoared and labelled as the solution (II). subsequently, $0.3 \mathrm{~g}$ PVP was added to both (I) and (II), and the mixtures were stirred for another 30 minutes to achieve complete dissolution. Furthermore, solution (I) containing Ag+ ions was combined with solution (II) containing W6+ ions and agitated for 30 minutes at room temperature to form the final solution (III). The supernatant was then centrifuged, rinsed with deionized water and ethanol, and dried for 24 hours at 60 degrees Celsius.

The scheme of the synthesis is depicted in Figure 1.

\section{Characterization Of Agwo}

The as-synthesized $\mathrm{Ag}_{2} \mathrm{WO}_{4}$ was subjected to various advanced characterizations to determine its physical, chemical, structural, and functional entities. Field emission scanning electron microscopy (FESEM, JSM-7100F, JEOL, Singapore) and transmission emission microscopy (TEM, Thermofisher, Talos F200 S) revealed the physical dimension of $\mathrm{Ag}_{2} \mathrm{WO}_{4}$. The elemental composition was analyzed with the FESEM machine. X-ray diffraction was used to examine the crystal structure of the photocatalyst (XRD, Microstar Proteum 8, Bruker). The functional properties of the catalyst were confirmed by Fourier transform infrared spectroscopy (FTIR, PerkinElmer RX-1) using potassium bromide. The band-energy was determined using the Tauc plot and UV-Vis spectroscopy.

\section{Photocatalytic Study}

The typical photocatalytic degradation experiments were run according to the design of the experiment using JMP Pro 15 software and RSM. Parameters (independent variables) like $\mathrm{pH}$ ranged from 5.0-10.0, contact time from 2-8 hours, catalyst dosage of $10-100 \mathrm{mg}$, and pollutant concentration of $10-100 \mathrm{mg} / \mathrm{L}$ or ppm. The experimental studies were carried out under sunlight (average sunlight intensity $=15285$ Lumen $/ \mathrm{m}^{2}$ ) as per the design. Te concentration of 2,4-DCP was monitored using UV-Vis spectrophotometer (Agilent Cary 60 Spectrophotometer) where the maxima $\left(\lambda_{\max }\right)$ was at $292 \mathrm{~nm}$. The degradation percentage was calculated using Eq (1) (Zabihi et al. 2015), The concentrations of 2,4-DCP at time $0 \mathrm{~h}$ and time $\mathrm{h}$ of the photocatalytic run are $\mathrm{C}_{0}$ and $\mathrm{C}_{\mathrm{t}}$, respectively. 


$$
\% \text { Degradation }=\left(1-\frac{C_{t}}{C_{0}}\right) * 100
$$

\section{Experimental Design For Rsm}

RSM compiled several statistical and mathematical methodologies that can be used to assess the relevance of various process factors. The reaction was analyzed using JMP Pro 15 software, and the predicted findings were calculated using the experimental design. Four variables with two central points and single replicates as the response were explored to determine the operating parameters for maximal deterioration of 2,4 DCP. Four independent parameters were taken into account: (i) pollutant concentration, (ii) catalyst dosage, (iii) contact time, and (iv) $\mathrm{pH}$. The operational levels and ranges of independent variables investigated in this study are shown in Table 1. Table 2 shows the results of the seven experimental runs generated using the RSM method and custom design of JMP software. To investigate the impact of independent variables on the experimental investigation, the response percentage degradation of 2,4-DCP was calculated. To fit the experimental data, a model was developed that correlates the independent variables.

Table 1

Operating levels and independent variable ranges

\begin{tabular}{|llll|}
\hline Level & Factors & Lower Limit & Upper Limit \\
\hline 1 & Pollutant concentration & $10 \mathrm{ppm}$ & $100 \mathrm{ppm}$ \\
\hline 2 & Catalyst dosage & $10 \mathrm{ppm}$ & $100 \mathrm{ppm}$ \\
\hline 3 & $\mathrm{pH}$ & 5 & 10 \\
4 & Contact time & $2 \mathrm{~h}$ & $8 \mathrm{~h}$ \\
\hline
\end{tabular}


Table 2

Experimental trials generated using Custom design - RSM method

\begin{tabular}{|llll|}
\hline Pollutant concentration $(\mathbf{p p m})$ & Catalyst dosage $(\mathrm{mg})$ & $\mathrm{pH}$ & Contact time (h) \\
\hline 100 & 10 & 5 & 8 \\
\hline 10 & 100 & 5 & 2 \\
\hline 55 & 55 & 7.5 & 5 \\
\hline 10 & 10 & 10 & 2 \\
\hline 100 & 100 & 10 & 2 \\
\hline 55 & 100 & 10 & 8 \\
\hline
\end{tabular}

\section{Results And Discussion}

\section{Characterization of $\mathrm{Ag}_{2} \mathrm{WO}_{4}$}

Microscopic approach was used to analyze the morphology of as-synthesized $\mathrm{Ag}_{2} \mathrm{WO}_{4}$. Fig. 2 (a) and (b) shows the FESEM micrographs, captured at $\times 2,500$ and $\times 5,000$ magnifications, respectively. It is evident that $\mathrm{Ag}_{2} \mathrm{WO}_{4}$ has attained flower-like structures. Further, TEM was used to examine the detailed physical entity of $\mathrm{Ag}_{2} \mathrm{WO}_{4}$. The TEM micrographs of $\mathrm{Ag}_{2} \mathrm{WO}_{4}$ are shown in Fig. 2 (c) and (d) confirming the flowerlike structures.

EDX analysis was used to determine the material's elemental composition. Fig. 2 (e) along with the inset table presents the percent weight of each element in the material. Notably, silver (Ag), oxygen ( 0 ), and tungsten $(\mathrm{W})$ are showing respective peaks that correspond to their respective $\mathrm{K}$ shell, $\mathrm{L}$ shell, and $\mathrm{K}$ shell transitions, respectively. The sample comprises $45.6 \% \mathrm{Ag}, 17.8 \% \mathrm{O}$, and $36.6 \% \mathrm{~W}$, with atomic percentages of $64.1 \%, 24.4 \%$, and $11.5 \%$, respectively. The EDX results highlight the successful synthesis of $\mathrm{Ag}_{2} \mathrm{WO}_{4}$ with no additional trace elements.

The crystallographic data were collected using XRD, with the Cu K-radiation assisting the $2 \theta$ angular measurements between $10^{\circ}$ and $80^{\circ}$ at a scan rate of $2^{\circ} / \mathrm{min}$. The XRD pattern for as-synthesized Ag2WO4 nano-flowers is shown in Fig. 3 (a). The intense peaks at $29.28^{\circ}, 31.49^{\circ}, 35.61^{\circ}, 44.48^{\circ}$, and $53.03^{\circ}$ were similar to those in JCPDS file Number 861157 and earlier literature (Roca et al. 2017). The Ag2W04 produced has high crystallinity, as evidenced by the narrow and sharp diffraction pattern.

Further, $\mathrm{Ag}_{2} \mathrm{WO}_{4}$ was studied by FTIR, and the spectrum is shown in Fig. 3(c). The broad peak at 3781.73 $\mathrm{cm}^{-1}$ may be assigned to the stretching vibration of the $\mathrm{O}-\mathrm{H}$ bond due to surface hydration. The peak at $1604.69 \mathrm{~cm}^{-1}$ corresponds to $\mathrm{W}-\mathrm{O}-\mathrm{H}$ bending. Two peaks at $784.11 \mathrm{~cm}^{-1}$ and $1102.30 \mathrm{~cm}^{-1}$ were due to the bridging stretching modes of W-O and W-O-W, respectively. An intense peak at $471.08 \mathrm{~cm}^{-1}$ was 
observed, which was ascribed to the characteristic asymmetric stretching vibration of O-W-O bonds within the distorted $\left[\mathrm{WO}_{6}\right]$ clusters. The peak at $784.11 \mathrm{~cm}^{-1}$ was attributed to the stretching modes of $\mathrm{W}-\mathrm{O}$ in $\mathrm{WO}_{6}$ octahedra (Nubla and Sandhyarani 2020; Elgorban et al. 2021).

The UV-Vis spectra revealed the light scattering capability, which was used to determine the bandgap of as-prepared semiconductor material (Makuła et al. 2018). The UV-Vis spectra were obtained in the range of 280-800 nm as shown in Fig. 2 (c). The optical bandgap $\left(E_{g}\right)$ was found to be $2.8 \mathrm{eV}$, which could be compared to previous studies (Shi et al. 2016; Andrade Neto et al. 2020). Eq (2) was used to compute $E_{g}$, where $a$ is the absorption coefficient, $h$ is the Planck constant, $v$ is the frequency, and $h v$ is the incident photon energy. The curve of ahu versus hu for $\mathrm{Ag}_{2} \mathrm{WO}_{4}$ is shown in Fig. 2 (c).

$$
(\alpha h v)^{2}=A\left(h v-E_{g}\right)
$$

\section{Response Surface Modeling For 2,4-dcp Degradation}

RSM analysis was conducted to optimize degradation at each design level using four different variables and seven different tests. Over the course of each experiment, the phenol residual concentration was calculated at regular intervals, and The phenol degradation rate was calculated using the final data (percent). The response factor was 2,4-DCP degradation (percent), and the calculated data over multiple variable-level sequences were statistically behaved to create the model. The connection between predicted and actual data, as shown in Fig. 4, is used to determine if the model is significant or insignificant for phenol removal. The anticipated $\mathrm{R}^{2}$ for phenol degradation is 0.98 . The model's relevance is also checked in terms of F-value, P-value, and sufficient precision. The root mean square error is 6.7951 , and the probability value is 0.0472 .

Table 3

Analysis of variance report

\begin{tabular}{|lllll|}
\hline Source & DF & Sum of Squares & Mean Square & F Ratio \\
\hline Model & 4 & 3773.0824 & 943.271 & 20.4290 \\
\hline Error & 2 & 92.3462 & 46.173 & Prob > F \\
\hline C. Total & 6 & 3865.4286 & & $0.0472^{\star}$ \\
\hline
\end{tabular}

The total sum of squares is the sum of the squared differences between the response values and the sample mean. It refers to the entire spectrum of possible responses (3773.0824). The erroneous sum of squares is the sum of squared differences between the fitted and actual values. It illustrates the variability that the model is unable to account for (92.3462). The model sum of squares is the difference between the total sum of squares and also the error sum of squares, and it represents the variability 
explained by the model. In this case, the model's explained variability is 3773.0824 , which is much higher than the 92.3462 that remains unexplained. The sum of squares divided by the relevant degree of freedom yields the mean square.

The $\mathrm{F}$ ratio is a statistical test that compares the error mean squares of the model with the error mean squares of the model. The $F$ test has a p-value of Prob. $>F$. The $p$-value is used to determine the statistical significance of a finding under a null hypothesis. The p-value indicates the possibility of getting an $\mathrm{F}$ ratio as high as that observed. In other words, a low p-value suggests that if the null hypothesis were true, such an extreme observed outcome would be exceedingly implausible. The Prob. > $F$ is less than 0.0001, indicating that the model has at least one significant effect.

The graphs of studentized residuals vs. run number and anticipated degradation, respectively, are shown in Fig. 5 (a) and (b). The residuals vs. run graph was quite helpful. lurking variables that may have influenced the response during experimental work were used to examine the acceptability of a constant variance plot of residuals vs. predicted values. As seen in Fig. 5 (b), they do not develop any evident pattern containing an abnormal structure. In addition, the expression of equal scatters down the $x$-axis demonstrates the sufficiency of the proposed model.

\section{Effects of independent operating parameters on pollutant removal.}

To visualise the influence of the independent operating factors on 2,4-DCP degradation, threedimensional (3D) response surfaces and contour plots were developed. Overall, the effective degradation of 2,4-DCP was observed with the higher dosage of photocatalyst, lesser pollutant concentration in alkaline medium and the study carried out for the longer duration. In addition, 85\% removal was observed with lesser contact time in acidic $\mathrm{pH}$ with higher dosage of catalyst. On the other hand, minimal removal efficiency was noted with the increased pollutant and photocatalyst dosage in the alkaline $\mathrm{pH}$ for lesser contact time. Fig. 6, 7, and 8 represents the 3D responses in the form of contour plots.

Figure 6 (a) is the 2,4-DCP removal as a function of catalyst dose and the pollutant concentration. It is seen that $91 \%$ degradation was achieved when the photocatalyst concentration was higher and the initial pollutant concentration was lesser. At a higher dosage of photocatalyst and pollutant concentration the degradation efficiency of 2,4-DCP was lesser. Figure 6 (b) shows the influence of $\mathrm{pH}$ and pollutant concentration on the photodegradation of 2,4-DCP. It is well established that pH between 5-8.5 and lower pollutant concentrations (10-45 ppm), there would be maximum mineralization of 2,4-DCP (>80\%). Conversely, in alkaline medium with higher contaminant load, the degradation rate decreases obviously.

The response simulated for the variation in $\mathrm{pH}$ and contact time is shown in Fig. 7 (a). Uniquely, the percentage degradation of 2,4-DCP reaches above $85 \%$ at two distinct operating conditions. Firstly, at $\mathrm{pH}$ of 8.5-10.0 and longer contact time of 7-8 $\mathrm{h}$, the degradation observed attains around $85 \%$. Secondly, the degradation reaches $80-85 \%$ at lower $\mathrm{pH}(5-6)$ for shorter contact time, as well as at neutral $\mathrm{pH}(7.5)$ for average run time. Hence, there exist a positive effect of $\mathrm{pH}$ on both pollutant concentration and contact time. Fig. 7 (b) illustrates the 3D response as the function of contact time and catalyst dosage. The 
simulated response unveil that, maximum degradation of the target is with the higher catalyst load and extended reaction time (Nourieh et al. 2020).

Figure 8 (a) notify on the variation of 2,4-DCP removal as a function of pollutant concentration and contact time. It is straightforward that, for a broad range of pollutant concentration (10-65 ppm) and contact duration of 4-8 h, approximately $80 \%$ or higher rate of degradation would be accomplished. Hence, the present system driven by $\mathrm{Ag}_{2} \mathrm{WO}_{4}$ stands potential under sunlight to treat 2,4-DCP. Finally, Figure 8 (b) represents the probable degradation with the influence of catalyst dosage and $\mathrm{pH}$ of reaction solution. The degradation percentage would reach above $80 \%$ at moderate $\mathrm{pH}$ of $5-6$ for higher catalyst loading (60-100 mg).

\section{Photocatalytic Mechanism}

The 2.4-DCP undergoes systematic breakdown under the action of sunlight and the $\mathrm{Ag}_{2} \mathrm{WO}_{4}$ catalyst. The typical photo-activation of the catalyst takes place upon absorbing suitable photons (energy $>E_{g}$ of $\left.\mathrm{Ag}_{2} \mathrm{WO}_{4}, 2.8 \mathrm{eV}\right)$. The redox reactions at the conduction and valence bands of $\mathrm{Ag}_{2} \mathrm{WO}_{4}$ generates reactive oxidants, that act on the 2,4-DCP to disintegrate the molecule, and finally forming simple organic compounds like water and carbon dioxide (Ali et al. 2020). The specific chemical reactions are represented in Eq 3-6. The Fig. 9 shows the schematic of photodegradation of 2,4-DCP using $\mathrm{Ag}_{2} \mathrm{WO}_{4}$.

$$
A g_{2} W_{4}+h \nu \rightarrow A g_{2} W O_{4}+h^{+}+e^{-}
$$

3

$$
h^{+}+\mathrm{H}_{2} \mathrm{O} \rightarrow \mathrm{OH}+\mathrm{H}^{+}
$$

4

$$
e^{-}+\mathrm{O}_{2} \rightarrow \mathrm{O}_{2}^{-} \rightarrow \mathrm{OH}^{-}
$$

5

$$
e^{-} \text {orh }^{+} \text {orO }_{2}^{-}+2,4-D C P \rightarrow \text { Intermediatecompounds }+\mathrm{CO}_{2}+\mathrm{H}_{2} \mathrm{O}
$$

Further, the possible degradation pathway includes the dehalogenation and ring fragmentation, forming few intermediates and finally resulting in chlorine ions, water, and carbon dioxide (Ai et al. 2019). Specifically, the 2,4-DCP adsorbed on the surface of $\mathrm{Ag}_{2} \mathrm{WO}_{4}$, firstly undergoes dechlorination to form ortho- and para-chlorophenols, and, phenol. Subsequently, these are reduced to para-benzoquinone, which in turn decomposes into benign intermediates and ions (Rakibuddin and Ananthakrishnan 2016). 


\section{Conclusions}

In summary, the present work showcases photocatalytic treatment of a toxic, yet recurrently occurring chlorophenol, 2,4-DCP in water and wastewater. The optimization of the whole process was done through $\mathrm{RSM}$, a reliable statistical tool. Specifically, a promising $\mathrm{Ag}_{2} \mathrm{WO}_{4}$ photocatalyst was synthesized easily by coprecipitation method and analyzed to confirm its intrinsic properties which, favored the photocatalytic action. There existed a reliable and convincible correlation between the experimental and predicted efficiencies with $R^{2}$ of 0.98 and probability index of 0.0472 . Further, the 3D responses generated based on response modeling revealed the significant influence of $\mathrm{pH}$, contact time, catalyst dose, and initial concentration of 2,4-DCP on the percentage removal. Finally, a plausible photocatalytic mechanism was proposed. Hence, the model presented is foreseen to be applied in real-time water and wastewater treatment.

\section{Declarations}

\section{Ethics approval}

Not applicable

\section{Consent for publication}

Not applicable

\section{Consent to Participate}

Not applicable

\section{Availability of data and materials}

All data generated or analyzed during this study are included in this article [and its supplementary information files].

\section{Competing interests}

The authors declare that they have no competing interests

\section{Funding}

Not applicable

\section{Author contributions}

RRexecuted the experiment and analysed the obtained results. BMG and SHKD assisted in interpretatins of the results. NPhypothesized and supervised the study. 


\section{Acknowledgments}

R., Rakshitha acknowledge the Ministry of Tribal Affairs, New Delhi, India, for "National Fellowship and Scholarship for Higher Education of S.T. Students", wide Award No.202021-NFST-KAR-00004for providingfinancial assistance. The authorsacknowledges JSS Academy of Higher Education and Research, Mysuru, for providing laboratory facility.

\section{References}

1. Adeleye AS, Conway JR, Garner K, et al (2016) Engineered nanomaterials for water treatment and remediation: Costs, benefits, and applicability. Chem Eng J 286:640-662. doi: 10.1016/j.cej.2015.10.105

2. Ai M, Qin W, Xia T, et al (2019) Photocatalytic degradation of 2,4-dichlorophenol by $\mathrm{TiO}_{2}$ intercalated talc nanocomposite. Int J Photoenergy 2019:1-11. doi: 10.1155/2019/1540271

3. Ali S, Humayun M, Pi W, et al (2020) Fabrication of $\mathrm{BiFeO}_{3}-\mathrm{g}-\mathrm{C}_{3} \mathrm{~N}_{4}-\mathrm{WO}_{3}$ Z-scheme heterojunction as highly efficient visible-light photocatalyst for water reduction and 2,4-dichlorophenol degradation: Insight mechanism. J Hazard Mater 397:122708. doi: 10.1016/j.jhazmat.2020.122708

4. Andrade Neto NF, Silva JMP, Tranquilin RL, et al (2020) Stabilization of the $\mathrm{\gamma}-\mathrm{Ag}_{2} \mathrm{WO}_{4}$ metastable pure phase by coprecipitation method using polyvinylpyrrolidone as surfactant: Photocatalytic property. Ceram Int 46:14864-14871. doi: 10.1016/j.ceramint.2020.03.012

5. Ataei A, Mehrizad A, Zare K (2021) Photocatalytic degradation of cefazoline antibiotic using zeolitesupported $\mathrm{CdS} / \mathrm{CaFe}_{2} \mathrm{O}_{4} \mathrm{Z}$-scheme photocatalyst: Optimization and modeling of process by RSM and ANN. J Mol Liq 328:115476. doi: 10.1016/j.molliq.2021.115476

6. Cen S, Lv X, Liu Q, et al (2021) Direct Z-scheme $\mathrm{Ag}_{2} \mathrm{WO}_{4} / \mathrm{BiOCl}$ composite photocatalyst for efficient photocatalytic degradations of dissolved organic impurities. Optik (Stuttg) 243:166847. doi: 10.1016/j.jileo.2021.166847

7. Elgorban AM, Al Kheraif AA, Syed A (2021) Construction of $\mathrm{Ag}_{2} \mathrm{WO}_{4}$ decorated $\mathrm{CoWO}_{4}$ nanoheterojunction with recombination delay for enhanced visible light photocatalytic performance and its antibacterial applications. Colloids Surfaces A Physicochem Eng Asp 629:127416. doi: 10.1016/j.colsurfa.2021.127416

8. Guerrero-Araque D, Ramírez-Ortega D, Acevedo-Peña P, et al (2020) Photocatalytic degradation of 2,4dichlorophenol on $\mathrm{ZrO}_{2}-\mathrm{TiO}_{2}$ : influence of crystal size, surface area, and energetic states. $\mathrm{J}$ Mater Sci Mater Electron 31:3332-3341. doi: 10.1007/s10854-020-02881-2

9. Hu K, Li Z, Chen S, et al (2018) Synthesis of Silicate-Bridged Heterojunctional $\mathrm{SnO}_{2} / \mathrm{BiVO}_{4}$ Nanoplates as Efficient Photocatalysts to Convert $\mathrm{CO}_{2}$ and Degrade 2,4-Dichlorophenol. Part Part Syst Charact 35:1700320. doi: 10.1002/ppsc.201700320

10. Huang S, Xu Y, Xie M, et al (2017) A Z-scheme magnetic recyclable Ag/AgBr@CoFe $\mathrm{O}_{4}$ photocatalyst with enhanced photocatalytic performance for pollutant and bacterial elimination. RSC Adv 
7:30845-30854. doi: 10.1039/c7ra03936k

11. Humaira $Y$, Amir Z, Shouxin L (2020) Surface plasmon resonance electron channeled through amorphous aluminum oxide bridged $\mathrm{ZnO}$ coupled g- $\mathrm{C}_{3} \mathrm{~N}_{4}$ significantly promotes charge separation for pollutants degradation under visible light. J Photochem Photobiol A Chem 400:112681. doi: 10.1016/j.jphotochem.2020.112681

12. Kokilavani S, Syed A, AL-Shwaiman HA, et al (2021) Preparation of plasmonic CoS/ $\mathrm{Ag}_{2} \mathrm{WO}_{4}$ nanocomposites: Efficient visible light driven photocatalysts and enhanced anti-microbial activity. Colloids Interface Sci Commun 42:100415. doi: 10.1016/j.colcom.2021.100415

13. Makuła P, Pacia M, Macyk W (2018) How To Correctly Determine the Band Gap Energy of Modified Semiconductor Photocatalysts Based on UV-Vis Spectra. J Phys Chem Lett 9:6814-6817. doi: 10.1021/acs.jpclett.8b02892

14. Malika M, Sonawane SS (2021) Statistical modelling for the Ultrasonic photodegradation of Rhodamine $\mathrm{B}$ dye using aqueous based $\mathrm{Bi}$-metal doped $\mathrm{TiO}_{2}$ supported montmorillonite hybrid nanofluid via RSM. Sustain Energy Technol Assessments 44:100980. doi: 10.1016/j.seta.2020.100980

15. Nagaraju P, Khunphonoi R, Puttaiah SH, et al (2017) Photocatalytic paraquat degradation over $\mathrm{TiO}_{2}$ modified by hydrothermal technique in alkaline solution. J Adv Oxid Technol 20:. doi: 10.1515/jaots2017-0004

16. Nagaraju P, Puttaiah SH, Wantala K, Shahmoradi B (2020) Preparation of modified ZnO nanoparticles for photocatalytic degradation of chlorobenzene. Appl Water Sci 10:137. doi: 10.1007/s13201-020-01228-w

17. Nourieh N, Nabizadeh R, Faramarzi MA, et al (2020) Photocatalytic degradation of ketoconazole by $\mathrm{Z}$-scheme $\mathrm{Ag}_{3} \mathrm{PO}_{4} /$ graphene oxide: response surface modeling and optimization. Environ Sci Pollut Res 27:250-263. doi: 10.1007/s11356-019-06812-5

18. Nubla K, Sandhyarani N (2020) Ag nanoparticles anchored $\mathrm{Ag}_{2} \mathrm{WO}_{4}$ nanorods: An efficient methanol tolerant and durable Pt free electro-catalyst toward oxygen reduction reaction. Electrochim Acta 340:135942. doi: 10.1016/j.electacta.2020.135942

19. Rafaely RX, Sabatini CA, Zaiat M, Azevedo EB (2021) Perfluorooctane sulfonic acid (PFOS) degradation by optimized heterogeneous photocatalysis $\left(\mathrm{TiO}_{2} / \mathrm{UV}\right)$ using the response surface methodology (RSM). J Water Process Eng 41:101986. doi: 10.1016/j.jwpe.2021.101986

20. Rafiq U, Majid K (2020) Mitigating the charge recombination by the targeted synthesis of $\mathrm{Ag}_{2} \mathrm{WO}_{4} / \mathrm{Bi}_{2} \mathrm{Fe}_{4} \mathrm{O}_{9}$ composite: The facile union of orthorhombic semiconductors towards efficient photocatalysis. J Alloys Compd 842:. doi: 10.1016/j.jallcom.2020.155876

21. Rakibuddin M, Ananthakrishnan R (2016) Effective photocatalytic dechlorination of 2,4dichlorophenol by a novel graphene encapsulated $\mathrm{ZnO} / \mathrm{Co}_{3} \mathrm{O}_{4}$ core-shell hybrid under visible light. Photochem Photobiol Sci 15:86-98. doi: 10.1039/c5pp00305a 
22. Roca RA, Lemos PS, Gracia L, et al (2017) Uncovering the metastable $\mathrm{y}-\mathrm{Ag}_{2} \mathrm{WO}_{4}$ phase: A joint experimental and theoretical study. RSC Adv 7:5610-5620. doi: 10.1039/c6ra24692c

23. Senthil RA, Osman S, Pan J, et al (2020) One-pot preparation of $\mathrm{AgBr} / \mathrm{a}-\mathrm{Ag}_{2} \mathrm{WO}_{4}$ composite with superior photocatalytic activity under visible-light irradiation. Colloids Surfaces A Physicochem Eng Asp 586:124079. doi: 10.1016/j.colsurfa.2019.124079

24. Shi L, Gou J, Liang L, et al (2016) The crystal phase transformation of $\mathrm{Ag}_{2} \mathrm{WO}_{4}$ through loading onto g- $\mathrm{C}_{3} \mathrm{~N}_{4}$ sheets with enhanced visible-light photocatalytic activity. RSC Adv 6:96861-96869. doi:

10.1039/C6RA18648C

25. Singh J, Soni RK (2021) Enhanced sunlight driven photocatalytic activity of In2S3 nanosheets functionalized $\mathrm{MoS}_{2}$ nanoflowers heterostructures. Sci Rep 11:15352. doi: 10.1038/s41598-02194966-z

26. Yashas SR, Sandeep S, Shivakumar BP, Swamy NK (2019) A matrix of perovskite micro-seeds and polypyrrole nanotubes tethered laccase/graphite biosensor for sensitive quantification of 2,4dichlorophenol in wastewater. Anal Methods 11:4511-4519. doi: 10.1039/c9ay01468c

27. Zabihi O, Khayyam H, Fox BL, Naebe M (2015) Enhanced thermal stability and lifetime of epoxy nanocomposites using covalently functionalized clay: Experimental and modelling. New J Chem 39:2269-2278. doi: 10.1039/c4nj01768d

28. Zulfiqar M, Samsudin MFR, Sufian S (2019) Modelling and optimization of photocatalytic degradation of phenol via $\mathrm{TiO}_{2}$ nanoparticles: An insight into response surface methodology and artificial neural network. J Photochem Photobiol A Chem 384:112039. doi:

10.1016/j.jphotochem.2019.112039

\section{Figures}

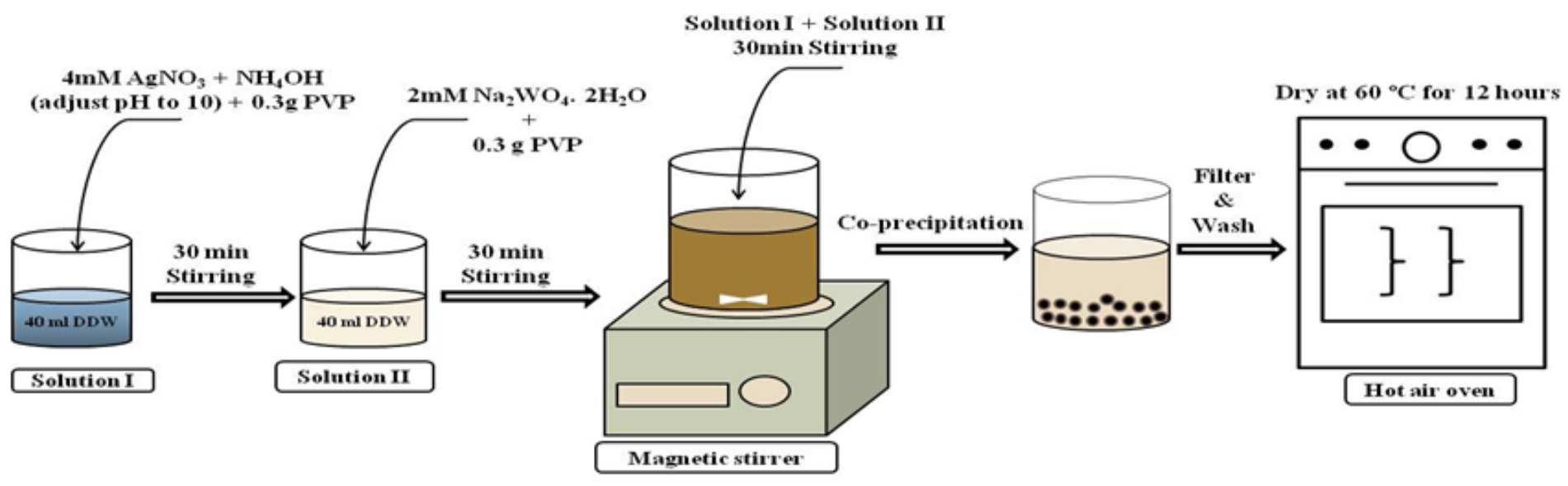

Figure 1

Schematic depict of the synthesis of $\mathrm{Ag}_{2} \mathrm{WO}_{4}$ by coprecipitation technique 


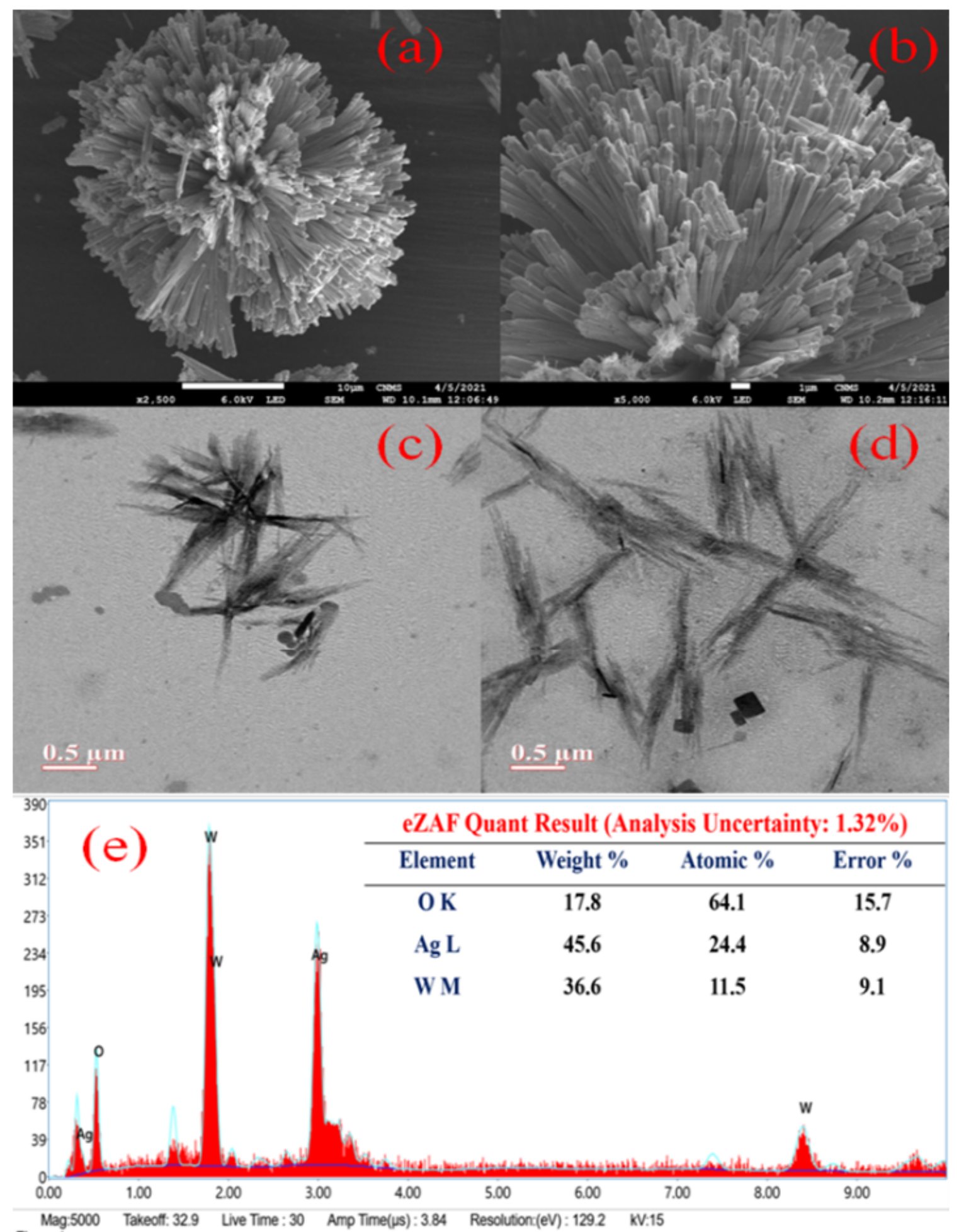

\section{Figure 2}

(a) and (b) FE-SEM micrograph of $\mathrm{Ag}_{2} \mathrm{WO}_{4}$, (c) and (d) HR-TEM of $\mathrm{Ag}_{2} \mathrm{WO}_{4}$, and (e)Elemental quantification of $\mathrm{Ag}_{2} \mathrm{WO}_{4}$ 

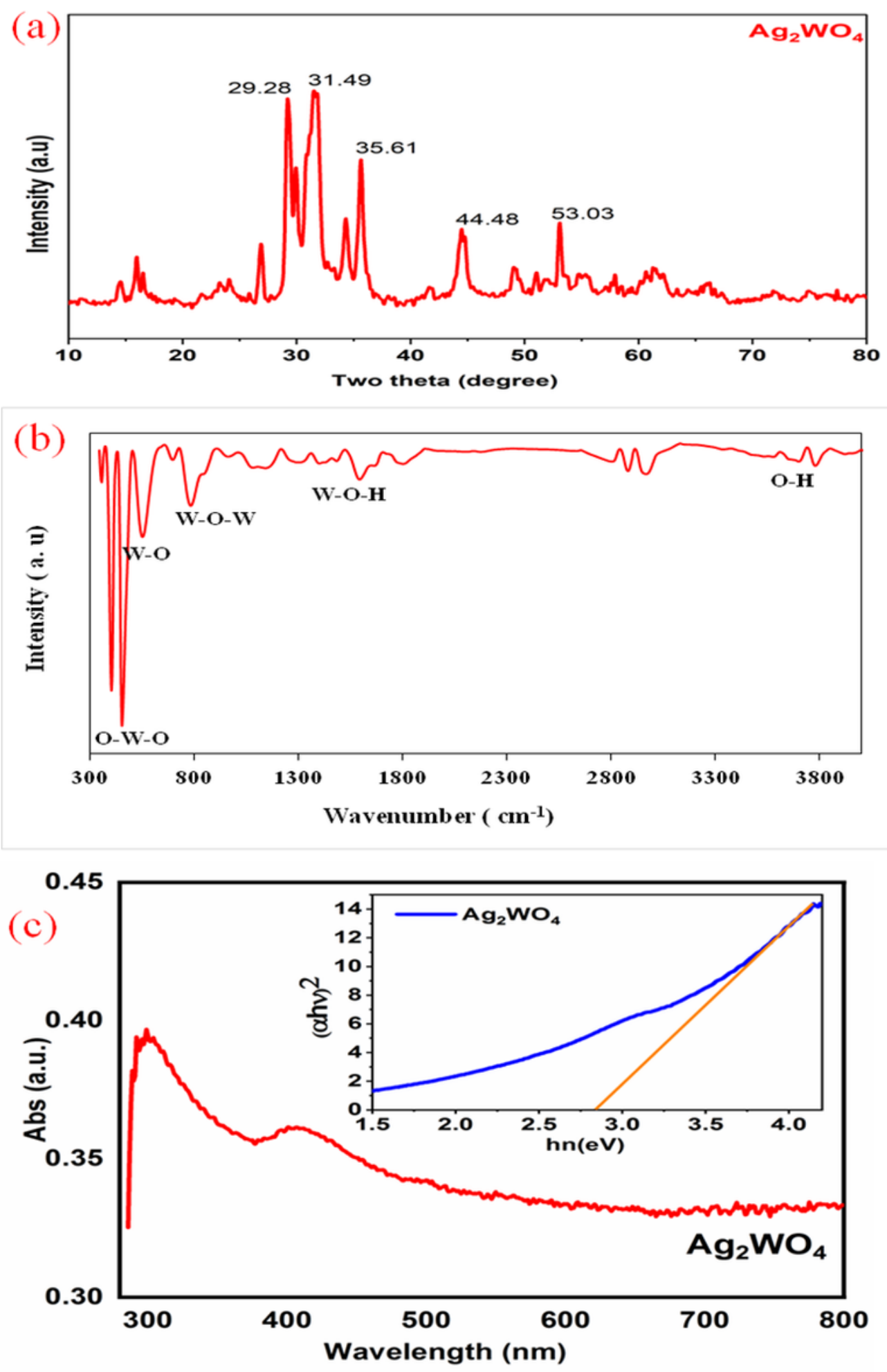

Figure 3

(a) XRD pattern of $\mathrm{Ag}_{2} \mathrm{WO}_{4}$, (b) FT-IR spectra of $\mathrm{Ag}_{2} \mathrm{WO}_{4}$, and (c) UV-visible spectra and Tauc plot forAg $\mathrm{WO}_{4}$ 


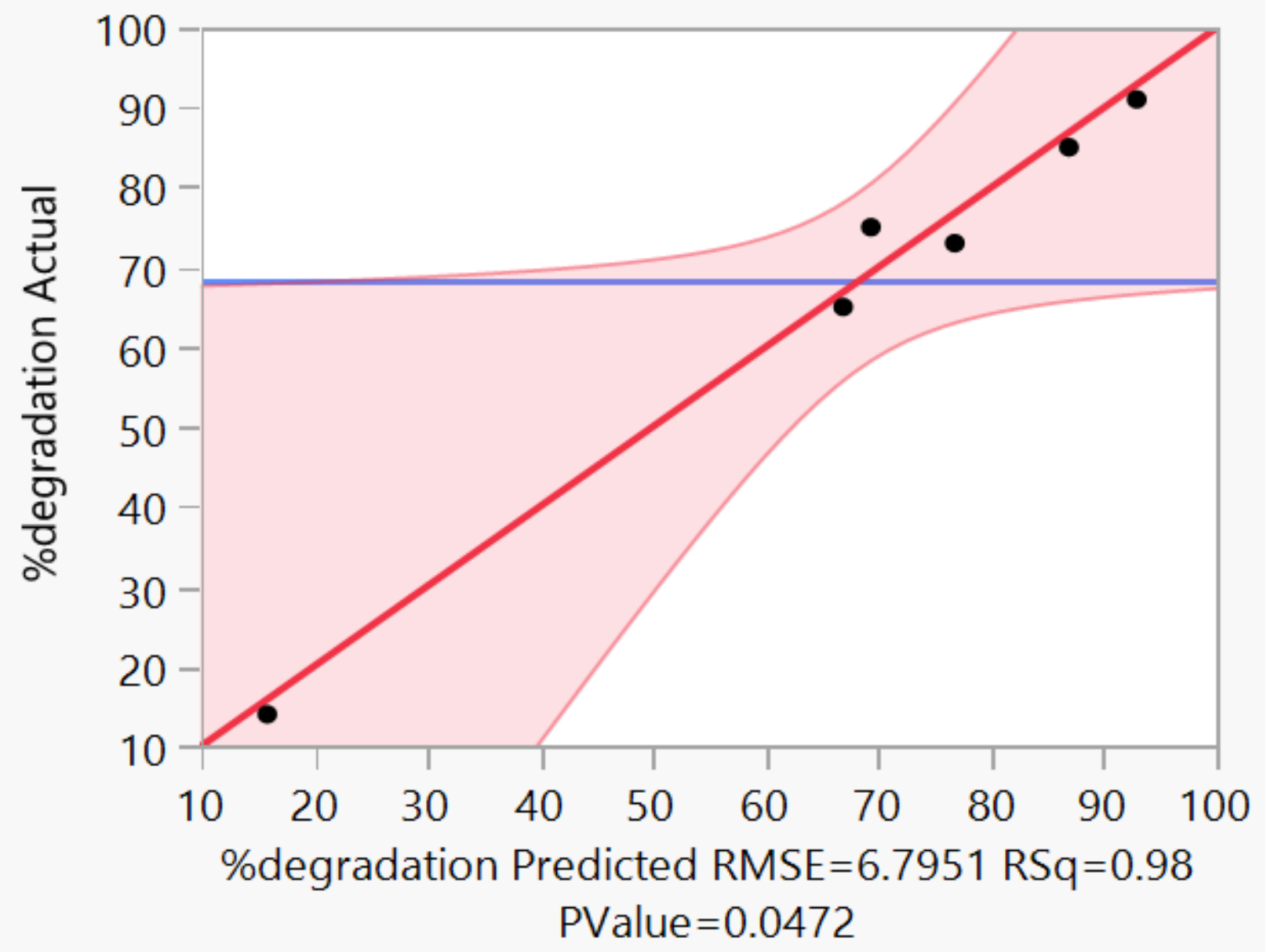

Figure 4

Values of observed percentage degradation as a function of the constructed model's predicted percentage degradation. The confidence interval and mean value of pollutant degradation are represented by the red area and blue line, respectively. 

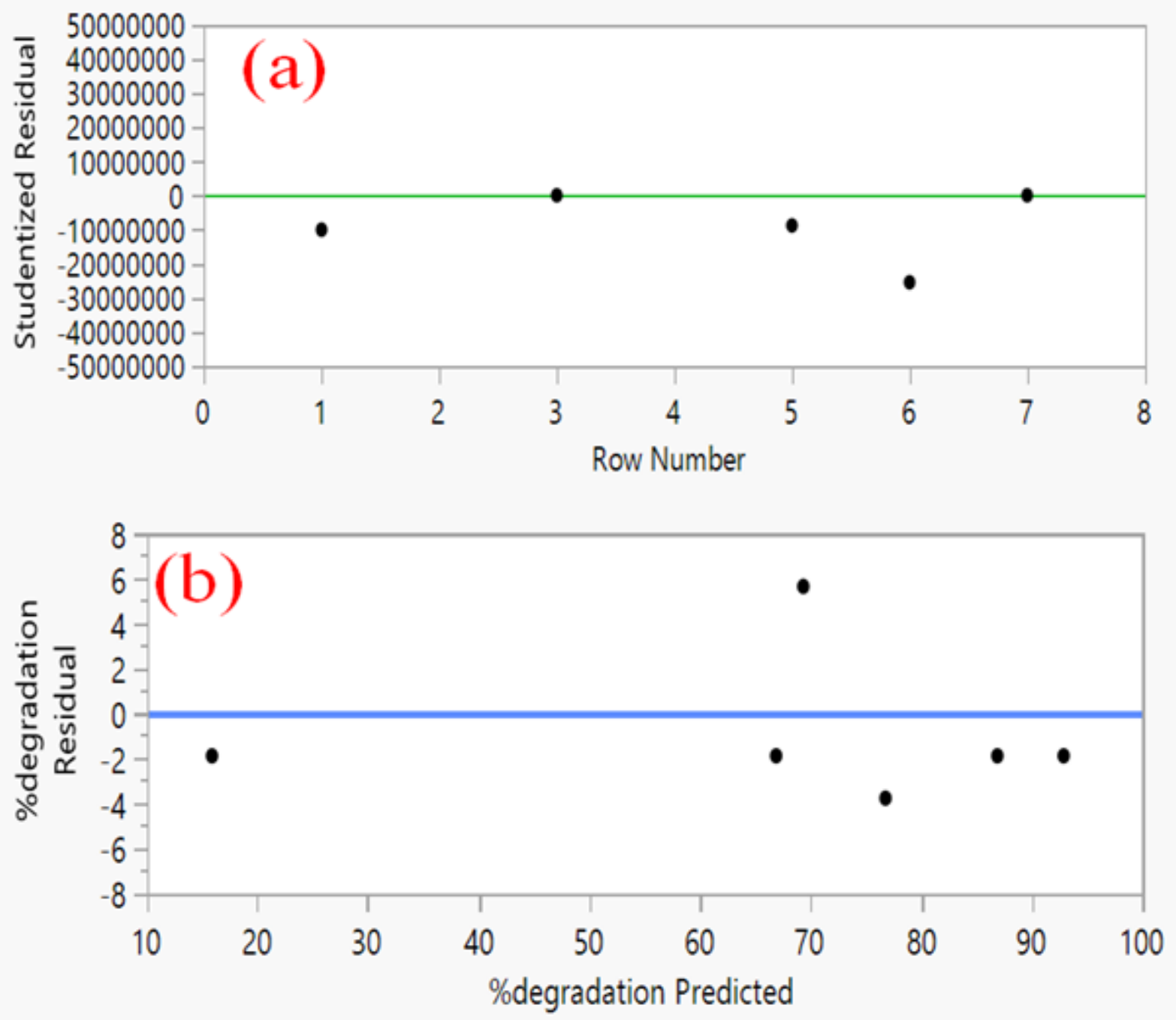

Figure 5

(a) Studentized Residual versus Row number and (b) Residual versus predicted for percentage degradation of 2,4-DCP 

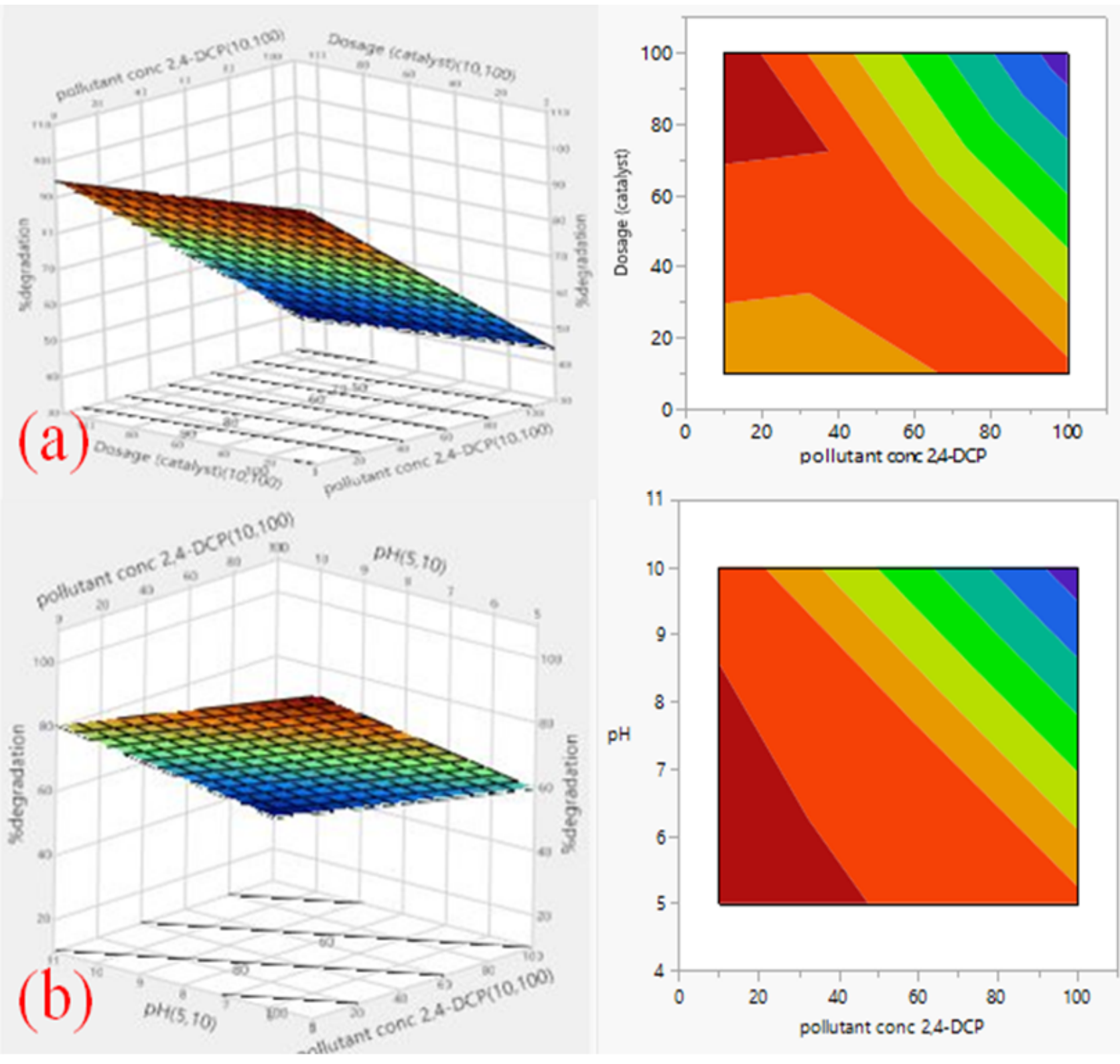

\%degradation

- $<20.0$

$\square<30.0$

$\square<40.0$

$\square<50.0$

$1<60.0$

$\square<70.0$

$\square<80.0$

$\square=80.0$

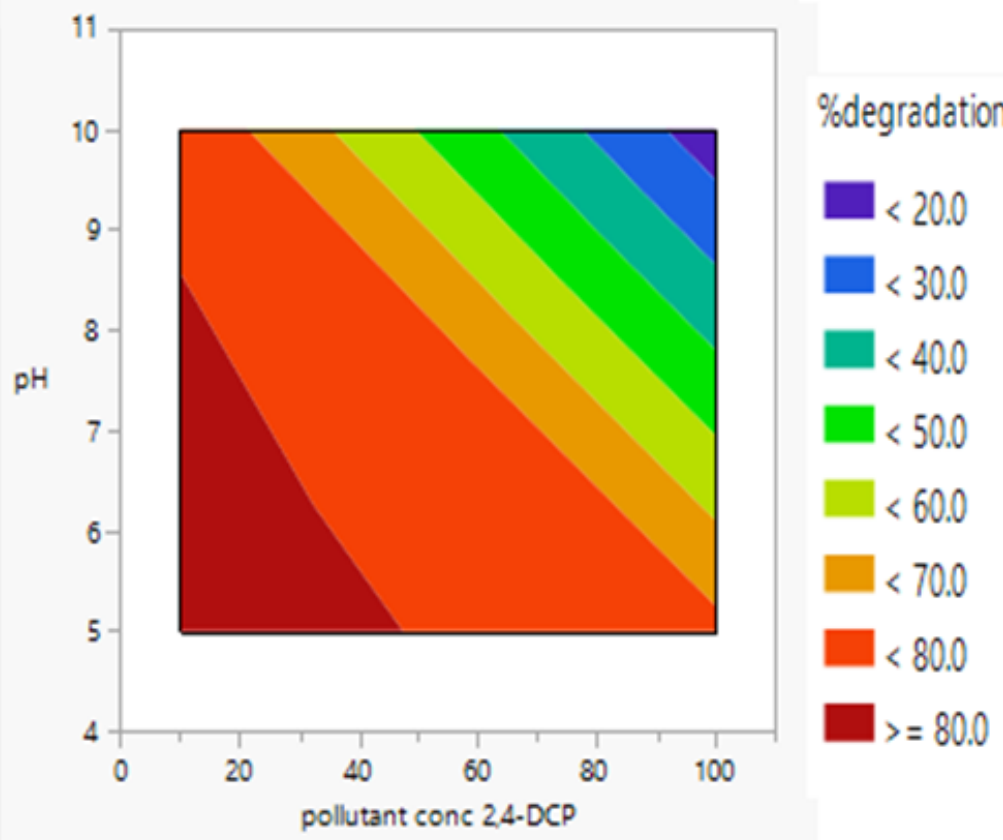

Figure 6

Response surface and contour plots showing the effects of the independent variables on the 2,4-DCP photodegradation, (a) effects of catalyst dosage and pollutant concentration on 2,4-DCP removaland (b) effects of $\mathrm{pH}$ and pollutant concentration on 2,4-DCP removal. 

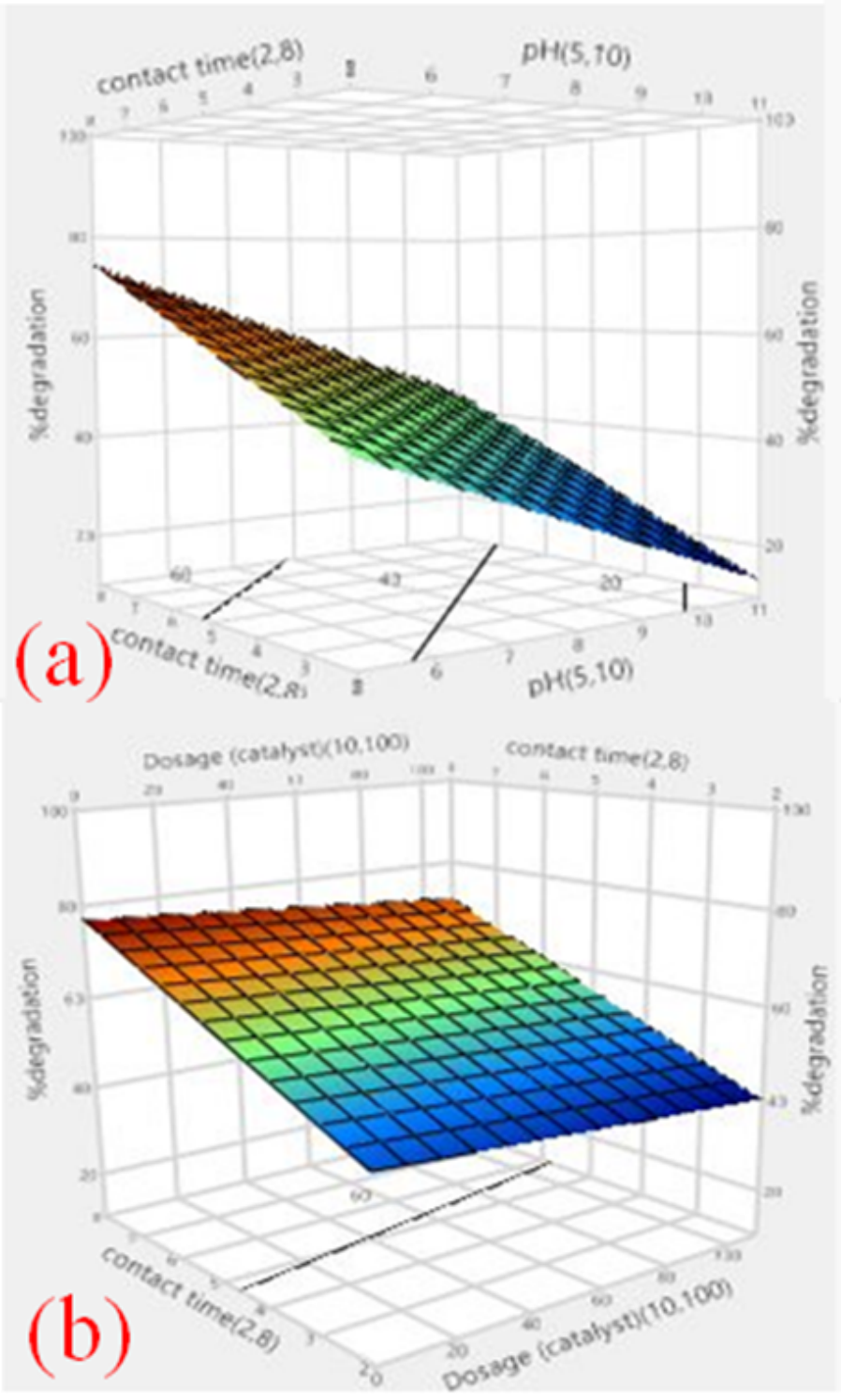
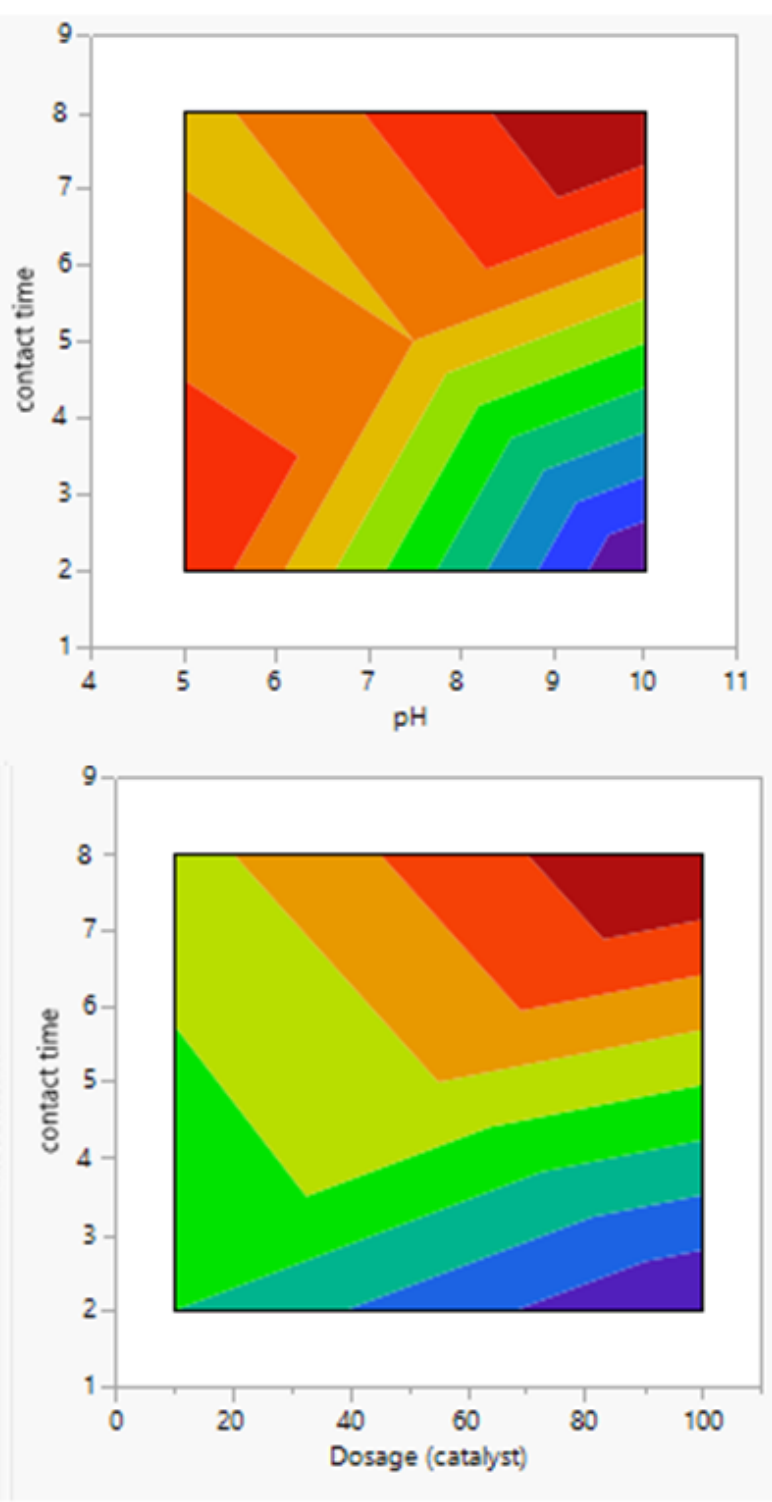

\%odegradation

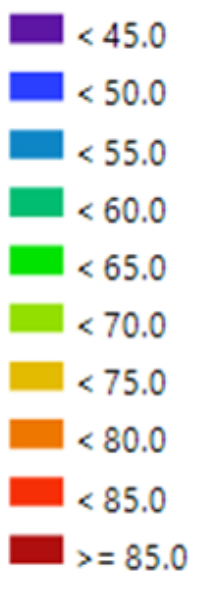

\%degradation

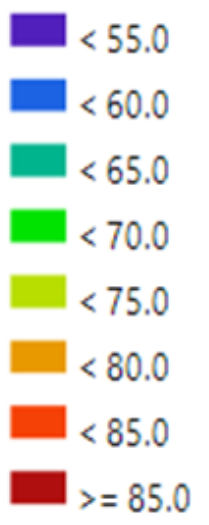

Figure 7

Response surface and contour plots showing the effects of the independent variables on the 2,4DCP photodegradation, (a) effects of contact time and $\mathrm{pH}$ on 2,4-DCP removal and (b) effects of contact time and catalyst dosage on 2,4-DCP removal. 

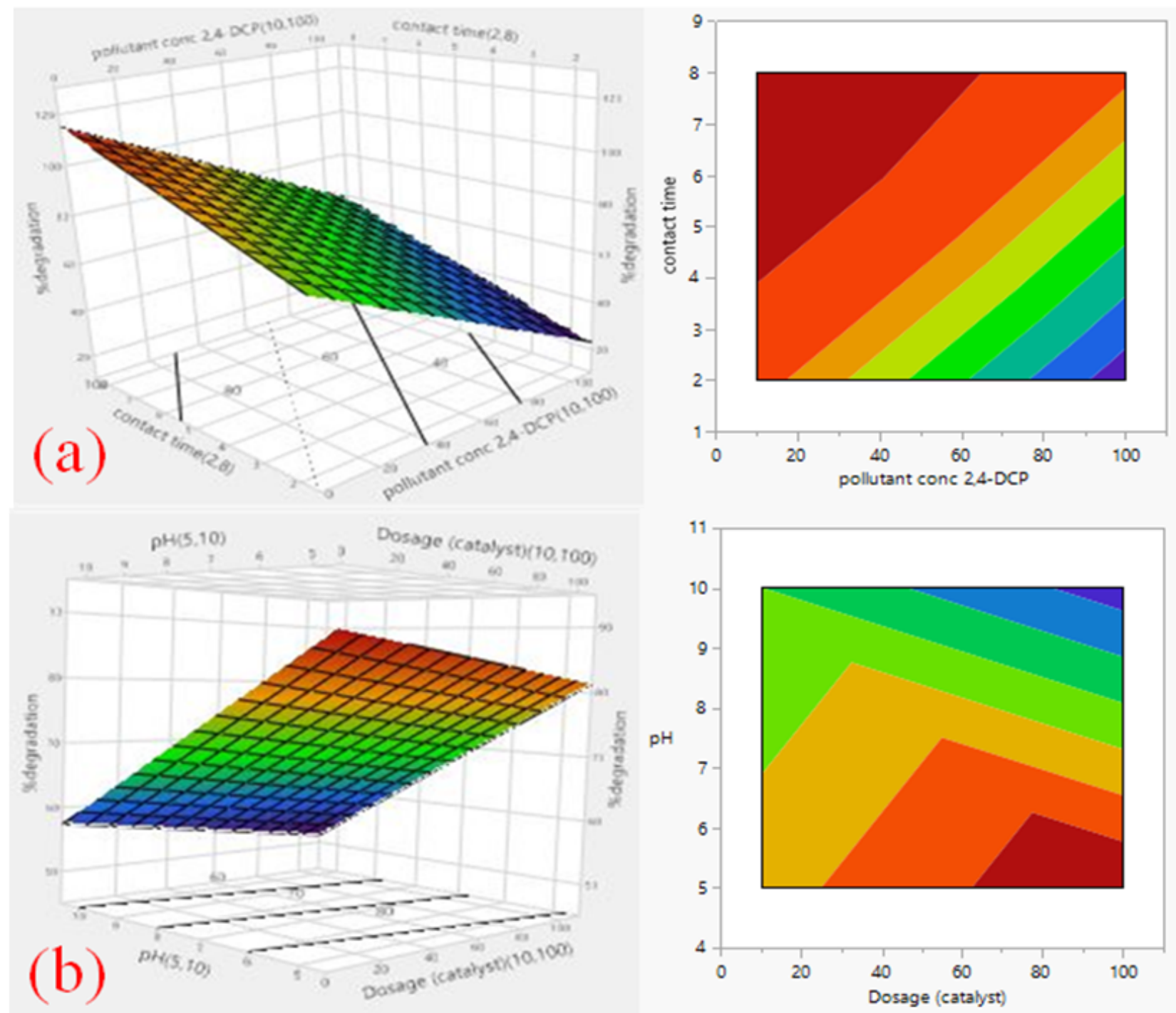

\%degradation

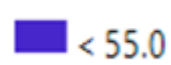

$<60.0$

$<65.0$

$<70.0$

$<75.0$

$<80.0$

$>=80.0$

Figure 8

Response surface and contour plots showing the effects of the independent variables on the 2,4 DCP photodegradation, (a) effects of contact time and pollutant concentration on 2,4 DCP removaland (b) effects of $\mathrm{pH}$ and catalyst dosage on 2,4 DCP removal. 


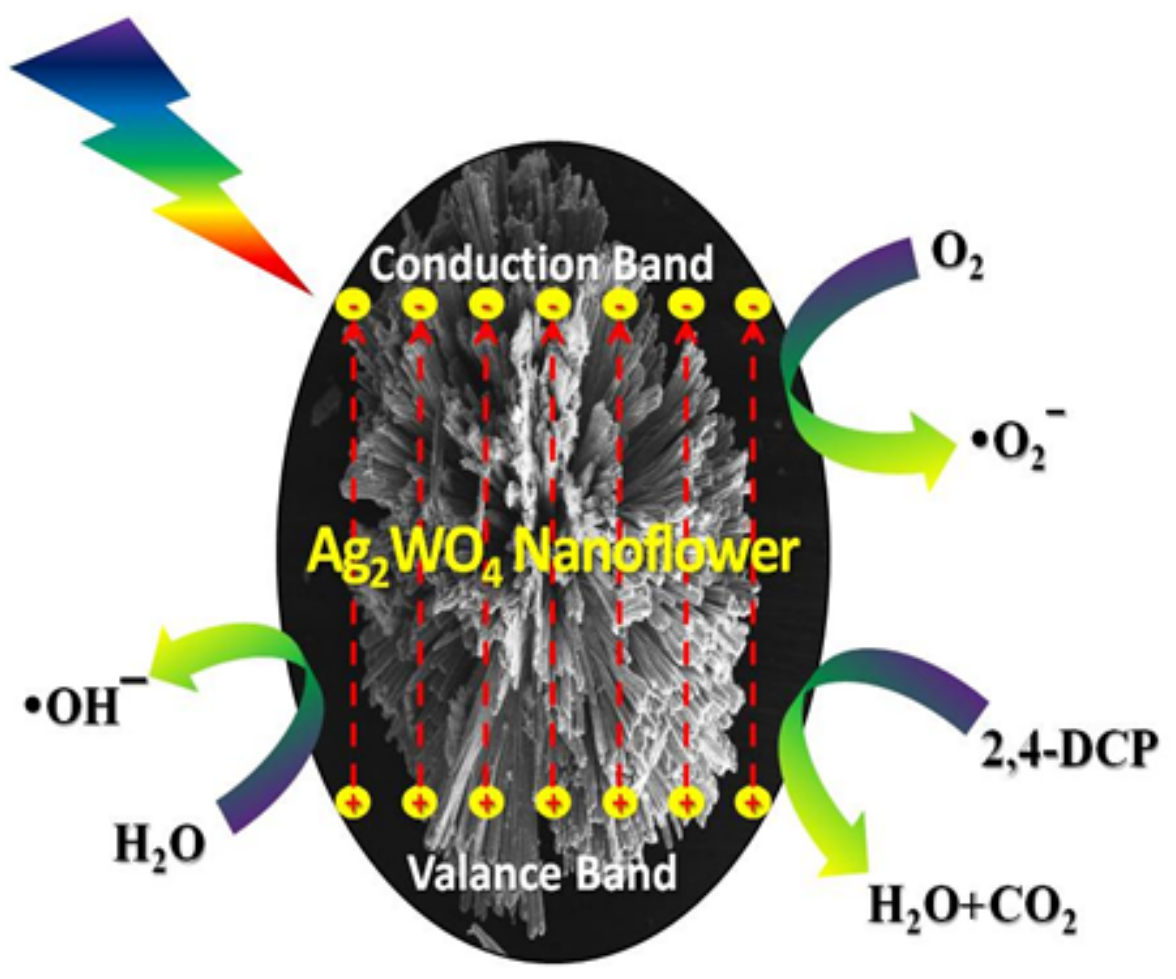

Figure 9

Schematic of photocatalytic removal of 2,4-DCP using $\mathrm{Ag}_{2} \mathrm{WO}_{4}$ under the sunlight irradiation 